\title{
Second Special Issue on Learning Analytics in Computing Education
}

\author{
ARI KORHONEN, Aalto University, Finland \\ SHUCHI GROVER, Palo Alto, USA
}

\section{INTRODUCTION}

This is the second part of the ACM Transactions on Computing Education (TOCE) Special Issue on Learning Analytics in Computing Education. The two-part special issue was assembled following a call to practitioners and researchers from numerous disciplines to submit manuscripts that address theoretical and empirical research on the use of learning analytics in the service of computer science education.

The two special issues include a collection of papers demonstrating empirical research and theory-based work on the use of learning analytics in computing education, including the ways in which data can be used to enhance the learning and teaching of computer science and programming and how learning analytics is helping advance our understanding of the teaching and learning of computing. We received 13 submissions at the intersection of learning analytics and computing education. Eight of them were accepted for publication in the special issue. Five papers were published in the first part of the special issue [1], and the remaining three are published in this second part of the special issue. Preference was given to empirical research.

\section{OVERVIEW OF PAPERS}

The article "An Improved Grade Point Average, with Applications to CS Undergraduate Education Analytics," by Jonathan Tomkin, Matthew West, and Geoffrey L. Herman, studies gender bias in academic achievement in computer science and other science, technology, engineering, and mathematics (STEM) courses. The research addresses the issue of a "GPA penalty"-the idea that fixed curves used by STEM faculty might artificially deflate student grades and GPAs, leading to inaccurate measures of students' overall academic ability. The article builds on an idea first proposed by Vanderbei et al. [2]: Biases in grade point averages (GPAs) can be corrected with a statistical model that combines student aptitude with course difficulty. Tomkin, West, and Herman present an improved method based on a logistic regression model to remove course selection effects in GPAs. The article compares these two models on a large dataset spanning 10 years of data and finds the logistic model to perform slightly better than the linear model proposed by Vanderbei et al. They choose gender as a specific case study, since women are more likely to leave computer science because of lower-than-expected grades/GPA in their STEM courses.

The article "How do Gender, Learning Goals, and Forum Participation Predict Persistence in a Computer Science MOOC?,” by R. Wes Crues, Genevieve M. Henricks, Michelle Perry, Suma Bhat,

Authors' addresses: A. Korhonen, PL 15400, FI-00076, AALTO, Finland; email: ari.korhonen@aalto.fi; S. Grover, 202 Sequoia Avenue, Palo Alto, CA 94306; email: shuchig@cs.stanford.edu.

Permission to make digital or hard copies of part or all of this work for personal or classroom use is granted without fee provided that copies are not made or distributed for profit or commercial advantage and that copies bear this notice and the full citation on the first page. Copyrights for third-party components of this work must be honored. For all other uses, contact the Owner/Author.

2018 Copyright is held by the owner/author(s).

1946-6226/2018/10-ART16

https://doi.org/10.1145/3243140 
Carolyn J. Anderson, Najmuddin Shaik, and Lawrence Angrave, draws connections and distinctions in the reasons women and men choose to enroll, participate, and persist in a Massive open online course (MOOC) on programming. They use gender, forum participation, and learning goals as factors to predict persistence in the course. The study showed that men and women gave very similar reasons for enrolling in the CS MOOC. However, in terms of forum participation among men and women, they found that (a) a greater proportion of women participated on the forum than men; (b) female participants were more likely to write at least one post to the course forum, while male participants were more likely to write nothing; (c) men taking the course to fulfill career aspirations were more likely to participate in the forums than other men; and (d) women taking the course because they were CS students were more likely to participate more substantially in the forums than other women. Last, they found that, for both men and women, posting to the forum led to more persistent participation compared with those just viewing or not viewing the forum.

In their article "Transfer Learning Methods in Programming Course Outcome Prediction," Jarkko Lagus, Krista Longi, Arto Klami, and Arto Hellas study machine-learning methods that learn to make predictions based on previously observed student behavior. The aim of the study was to predict the outcomes of two separate introductory programming courses. They not only diagnosed students at risk of failing their studies but also attempted to identify students who could benefit from additional challenges. They compared their results with those from traditional machine-learning approaches. The article also argues that differences among courses set huge challenges for the generalizability of machine-learning methods because traditional machine-learning methods (erroneously) assume that all teaching contexts are alike. The authors address this challenge by reviewing the concept of transfer learning, which relaxes the strict assumption of identical distributions for training and test data. This empirical study shows that transfer learning methods are able to improve predictions, especially when forecasting student performance at the very beginning of a course with a limited amount of training data.

\section{ACKNOWLEDGMENTS}

We are grateful to the authors who submitted their manuscripts to the special issue and then purposefully worked through the review process. We also thank all the reviewers for both special issues for their insightful comments and efforts to improve the manuscripts. Finally, thanks to the ACM TOCE editor-in-chief, Chris Hundhausen, for his valuable comments and support throughout the process of publishing the two-part Special Issue on Learning Analytics in Computing Education.

Ari Korhonen

Guest Editor

Shuchi Grover

Co-Guest Editor

\section{REFERENCES}

[1] S. Grover and A. Korhonen. 2017. Unlocking the potential of learning analytics in computing education. ACM Trans. Comput. Educ. 17, 3 (2017), 11e:1-11e:4.

[2] R. J. Vanderbei, G. Scharf, and D. Marlow. 2014. A regression approach to fairer grading. SIAM Rev. 56, 2 (2014), 337-352. 